\title{
Penicillinase-producing strains of Neisseria gonorrhoeae isolated in Rotterdam
}

\author{
F. B. BLOG, A. CHANG, G. A. J. DE KONING, A. P. ORANJE, AND \\ E. STOLZ
}

From the Department of Dermatology, University Hospital Rotterdam-Dijkzigt

G. BOSSCHER-KOETSIER, M. P. E. DE JONGE-SUY, M. F. MICHEL, E. O'NIEL, AND S. DE WEERDT-VAN AMEYDEN

From the Department of Clinical Microbiology, University Hospital Rotterdam-Dijkzigt

L. GAASTRA

From the Department of Venereology, Social Health Service, Rotterdam

SUMMARY This appears to be the first report of the isolation of a penicillinase-producing strain of Neisseria gonorrhoeae in the Netherlands. The presence of a penicillinase-producing gonococcal strain (PPGS) was demonstrated in two of a group of three patients with gonorrhoea. In addition, a penicillin- and ampicillin-sensitive gonococcus strain was isolated from all three patients. The PPGS was most probably imported into Holland from the Philippines. The epidemiological and clinical findings and the results of treatment of infection with this PPGS are discussed.

\section{Introduction}

One of the Morbidity and Mortality Weekly Reports from Atlanta, Georgia (Center for Disease Control, 1976) reported on the isolation of two penicillinaseproducing gonococcal strains (PPGS) in the USA. Both these strains had originated in the Philippines and the patients carrying them were treated, but without success, with 4.8 million units of aqueous procaine penicillin combined with $1 \mathrm{~g}$ of probenecid, given orally. The patients were cured by treatment with 2-4 $\mathrm{g}$ of spectinomycin hydrochloride intramuscularly. Since then reports of PPGS in the USA, England, and Australia have been made by Phillips (1976), Ashford et al. (1976), Turner et al. (1976), Golash et al. (1976), and Lindon and Handke (1976). In a leading article in the British Medical Journal (1976) most of these reports were cited and the problem of PPGS was discussed. Some PPGS have also been isolated in Scandinavia (personal communications). Attention has recently been paid to the PPGS problem in Holland (Nederlandsch tijdschrift voor geneeskunde, 1976; World Health Organisation, 1976).

It is important to note that the incidence of

Requests for reprints: E. Stolz, Department of Dermatology, University Hospital Rotterdam-Dijkzigt, Rotterdam, Holland

Received for publication 29 December 1976 infection with PPGS in the USA is low, and that many of these infections were imported into the USA from the Far East, particularly from the Philippines. A number of the strains isolated in England were imported from West Africa. However, as gonococcal strains isolated from certain populations in the Far East have been found to contain 30 to $40 \%$ of PPGS, further transmission of such strains to Europe and the USA is likely (personal communication).

As many of the PPGS isolated in the USA have been found to be resistant to tetracycline, treatment with spectinomycin hydrochloride has been recommended (personal communication).

Various authors have described tests which can be used to identify PPGS. Recently, Phillips et al. (1976) described a method that was fast and simple, based on the acid production when penicillin is split up to give penicilloic acid.

\section{PPGS in Rotterdam}

Warned and alarmed by these reports, we in Rotterdam have over the past few months been keeping deep-frozen samples of Neisseria gonorrhoae which did not respond to our usual ampicillin treatment of $1 \mathrm{~g}$ ampicillin intramuscularly followed after four hours by $4 \mathrm{~g}$ ampicillin orally (Stolz and Kerkkamp, 1974). As this treatment is nearly 
always successful, the number of strains we preserved in this way was small. Nevertheless, we recently succeeded in isolating and identifying a PPGS from a group of three patients. The strains were isolated and identified as described by Stolz et al. (1974), and the method described by Phillips et al. (1976) was used to demonstrate penicillinase production.

\section{PATIENTS}

\section{Patient 1}

On 23 November 1976, a 30-year-old man consulted our clinic. He complained of discharge and strangury which he had had since 17 November. The clinical investigation revealed a yellow discharge. The Gram-stained smear showed intra- and extracellular Gram-negative diplococci. The culture of pus from the urethra was positive for gonococci, while that from the oropharynx was negative.

The patient stated that he had had genito-genital contact with a stewardness (patient 3) on 13 November, while on 16 November he had had similar contact with his ex-wife, from whom he had recently been divorced (patient 2). Patient 1 was given ampicillin treatment. At the follow-up examination a week later, all complaints had disappeared. The Gram-stain of fluid from the urethra no longer showed Gram-negative diplococci, and the urethral culture was negative for gonococci.

\section{Patient 2}

A 29-year-old woman also consulted our clinic on 23 November, independently of her ex-husband. She complained of a yellowish discharge, burning on micturition, and vulval itch. She stated that the contact already mentioned by patient 1 was the only sexual contact she had had recently.

Examination revealed a small amount of whitishyellow discharge. The Gram-stained smear of pus from the urethra showed Gram-negative diplococci, while that of pus from the cervix did not. Gonococci could not be cultured from the oropharynx, but they could be from the cervix, urethra, and rectum.

This patient was also given the normal ampicillin treatment, but without success. At follow-up examinations on 1 and 2 December gonococci could still be cultured from the cervix, urethra, and rectum. The patient was adamant, even after long and intensive questioning, that she had had no new sexual contact since the treatment.

Because of the failure of the treatment, we investigated to see if the gonococcal strains isolated from the patient produced penicillinase. The strain which had been isolated and preserved before treatment, the one from the urethra, was found to be a non-PPGS. Before this finding was known, we had repeated our standard ampicillin treatment on the patient; after the first and second ampicillintreatments PPGS were cultured from her cervix and urethra. When the follow-up examination showed that this second treatment had also failed, she was successfully treated with $3.2 \mathrm{~g}$ of spectinomycin sulphate (Delspectin) intramuscularly.

\section{Patient 3}

A 22-year-old woman, a stewardess, was approached by the contact-tracing section of the municipal socio-medical service, and asked to attend our clinic for examination. She did so on 3 December. She stated that as well as the contact mentioned by patient 1 on 13 November, she had had genitogenital contact with a Philippine steward of an airline company on 25 October. Shortly after this contact she had suffered from a. burning feeling during micturition. She, and the doctor who treated her, ascribed this to cystitis; she was given white tablets (not known to us), and the symptoms had diminished. At examination, a slight amount of whitish-yellow discharge was found, and Gramnegative diplococci were observed in the Gramstained smears of pus from the urethra and cervix. The cultures from the oropharynx and rectum were negative for gonococci, while those from the cervix and urethra were positive. She was examined again on 6 December, with identical results and was treated with $3.2 \mathrm{~g}$ of spectinomycin sulphate (Delspectin) intramuscularly. Shortly afterwards she left on a duty mission, and will not be available for examination for several weeks.

\section{FINDINGS}

The gonococcal strain isolated from the urethra of patient 3 was found to be a PPGS, while that from her cervix was not (examination of 3 December).

The gonococcal strain isolated from patient 1 was found not to be a PPGS.

The sensitivities of the strains isolated from patients 1, 2 and 3 for ampicillin, penicillin, and tetracycline were quantitatively determined by the method described by Stolz et al. (1974) and expressed as minimum inhibitory concentrations (MICs) in $\mu \mathrm{g} / \mathrm{ml}$. If the MIC for ampicillin and penicillin was $>2.56 \mu \mathrm{g} / \mathrm{ml}$, the strains were re-tested at penicillin and ampicillin concentrations of $5 \cdot 12,10 \cdot 24$, and $81.96 \mu \mathrm{g} / \mathrm{ml}$.

The MICs found for ampicillin were $0.04 \mu \mathrm{g} / \mathrm{ml}$ for strain A, 0.08 for strain B (urethra), 81.96 $(>10 \cdot 24)$ for strain C (urethra), and 0.08 for strain $\mathrm{C}$ (cervix).

The corresponding values for penicillin were: strain A 0.02 , strain B (urethra) 0.04 , strain C (urethra) $81.96(>10.24 \mu \mathrm{g} / \mathrm{ml}$ ), strain C (cervix 
$0.04 \mu \mathrm{g} / \mathrm{ml}$, and for tetracycline: strain A $0 \cdot 16$, strain B (urethra) 0.32 , strain C (urethra) 0.32 , and strain $\mathrm{C}$ (cervix) $0 \cdot 32$.

In a second examination, the strains from the urethra and cervix of patient 2 were found to have the same sensitivity, equal to that for strain $C$ (urethra) given above.

Attempts are being made to find the Philippine steward, who may have asymptomatic urethritis, and to persuade him to have treatment and an investigation at a clinic to see whether the strain isolated from him produces penicillinase.

All three patients were also examined for other sexually transmitted complaints, but none was found.

\section{Discussion}

It is interesting that patient 2 , a contact of patient 1 , did not respond to the normal ampicillin treatment while patient 1 did.

Our sensitivity determinations showed that patient 1 had only an ampicillin-sensitive, non-PPGS, while a PPGS and a non-PPGS could be isolated from patient 3 before ampicillin treatment. In patient 2 the strain isolated before ampicillin treatment was a non-PPGS while the strains isolated after ampicillin treatment were PPGS. However, the strains isolated from her cervix and rectum before ampicillin treatment were not tested for forming penicillinase, so the presence of PPGS in these sites cannot be excluded.

It is possible that patient 1 , who acted as carrier of the gonorrheal infection from patient 3 to patient 2, did not harbour the PPGS in his urethra, so that he could successfully be treated for gonococcal urethritis infection with an ampicillin- and penicillinsensitive gonococcus strain.

The fact that both a PPGS and a non-PPGS could be isolated from patients 2 and 3 is an interesting finding that has not been reported before to the best of our knowledge. It is also of note that the PPGS grew less well in vitro than the non-PPGS. One might speculate on whether these two strains were originally one, the PPGS having arisen from the originally ampicillin-. and penicillin-sensitive strain ( $R$ factor?). The fact that patient 2 had a non-PPGS before ampicillin treatment, while only a PPGS could be isolated after treatment, illustrates the ease with which ampicillin- and penicillinsensitive gonococcal strains can be eliminated, and PPGS selected, by inadequate treatment.

The PPGS isolated by us showed no signs of resistance to tetracycline. The boundary between sensitivity and resistance to tetracycline has been determined in previous investigations as an MIC $\geqslant 1.28 \mu \mathrm{g} / \mathrm{ml}$ (Stolz et al., 1974). It now appears that patients 2 and 3 could have been successfully treated with tetracycline; however, at the time of the spectinomycin-sulphate treatment the results of the sensitivity tests were not known.

It is important to know how the PPGS was brought to Holland. As these case histories show, it was not immediately clear that the strain had been imported from the Philippines; this was only revealed by the history of patient 3 . This emphasises the importance of good contact tracing and proper history taking. The speed with which a PPGS can be propagated round the world is illustrated by the fact that two of the four people involved were employees of an airline company.

The Center for Disease Control in Atlanta advises treatment with $2 \mathrm{~g}$ of spectinomycin hydrochloride (Trobicin) intramuscularly for infections with PPGS which do not respond to treatment with penicillin or ampicillin. In Holland, only Delspectin (spectinomycin sulphate) $1.6 \mathrm{~g}$ intramuscularly is available; this is why we treated patient 3 (and finally also patient 2) with $3.2 \mathrm{~g}$ of spectinomycin sulphate (to be on the safe side). It might have been enough to give $1.6 \mathrm{~g}$ spectinomycin sulphate intramuscularly.

We would like to urge all physicians treating gonorrhoea that if treatment with penicillin/ ampicillin fails, the strains should be isolated, identified, and tested for penicillinase production. The test method described by Phillips et al. (1976) can be carried out in any laboratory.

\section{References}

Ashford, W. A., Golash, R. G., and Hemming, V. G. (1976). Penicillinase-producing Neisseria gonorrhoeae. Lancet, 2, 657-658. British Medical Journal (1976). Leading article: Penicillinaseproducing gonococci. British Medical Journal, 4, 963-964.

Center for Disease Control (1976). Penicillinase-producing Neisseria gonorrhoeae. Morbidity and Mortality Weekly Report, 25, 261.

Golash, R. G., Hemming, V. G., Ashford, W. A., Moore, F. D. Waller, T. J., Bettinger, J. J., and Presley, C. C. (1976). Letter to the Editor: Penicillinase-producing Neisseria gonorrhoeae. Lancet, 2, 793-794.

Lindon, M., and Handke, G. (1976). Penicillinase-producing Neisseria gonorrhoeae in Adelaide. Medical Journal of Australia, 2, 660.

Nederlandsch tijdschrift voor geneeskunde (1976). Editorial: Epidemiologische Mededelingen, Penicillinase vormende gonokokkenstammen! Nederlandsch tijdschrift voor geneeskunde, 120, 1923-1924.

Phillips, I. (1976). $\beta$-Lactamase-producing, penicillin-resistant gonococcus. Lancet, 2, 656-657.

Phillips, C. W., Aller, R. D., and Cohen, S. N. (1976). Letter to the Editor: Penicillinase-producing Neisseria gonorrhoeae. Lancet, 2, 960.

Stolz, E., and Kerkkamp, H. J. J. (1974). Treatment of gonorrhoea using a combination of intramuscular and oral ampicillin. British Journal of Venereal Diseases, 50, 442-446.

Stolz, E., Zwart, H. G. F., and Michel, M. F. (1974). Sensitivity to ampicillin, penicillin, and tetracycline of gonococci in Rotterdam. British Journal of Venereal Diseases, 50, 202-207.

Turner, G. C., Ratcliffe, J. G., and Anderson, D. (1976). Letter to the Editor: Penicillinase-producing Neisseria gonorrhoeae. Lancet, 2, 793.

World Health Organisation. (1976). Neisseria gonorrhoeae producing penicillinase. Weekly Epidemiological Records, 51, 293. 